\title{
Major Salivary Gland Cancer by AJCC v7 Stage
}

National Cancer Institute

\section{Source}

National Cancer Institute. Major Salivary Gland Cancer by AJCC v7 Stage. NCI Thesaurus.

Code C132778.

A term that refers to the staging of major salivary gland cancer according to the American Joint Committee on Cancer, 7th edition. 